\title{
LOS TEXTOS DE HISTORIA: UNA CONSTANTE PREOCUPACIÓN EN LA PRODUCCIÓN DE JORGE BRACHO
}

\section{THE TEXTS OF HISTORY: A CONSTANT CONCERN IN THE PRODUCTION OF JORGE BRACHO}

\begin{abstract}
María Elena Del Valle Mejías ${ }^{1}$. Universidad Metropolitana de Caracas. Venezuela. manedelvalle@gmail.com
\end{abstract}

\section{RESUMEN}

El presente artículo resume las principales reflexiones realizadas por Jorge Bracho en torno a la enseñanza de la Historia de Venezuela. En él se describen sus principales preocupaciones en relación a las características de los textos escolares usados en la enseñanza de la Historia de Venezuela.

PALABRAS CLAVE: textos escolares, historia de Venezuela, enseñanza.

\section{ABSTRACT}

This article summarizes the main reflections made by Jorge Bracho about the teaching of the History of Venezuela. It describes his main concerns regarding the characteristics of school texts used in the teaching of the History of Venezuela.

KEY WORDS: textbooks, history of Venezuela, teaching.

\section{Cómo citar el artículo:}

Del Valle Mejías, M. E. (2017). Los textos de historia: una constante preocupación en la producción de Jorge Bracho. Revista de Ciencias de la Comunicación e Información, 22(1), 11-17.

doi: http://doi.org/10.35742/rcci.2017.22(1).11-17

\footnotetext{
${ }^{1}$ María Elena Del Valle Mejías: graduada como Profesora en la Universidad Pedagógica Libertador en el año 1992, especialización en Historia Económica y Social de Venezuela en la Universidad Santa María. Maestría en Historia Económica y Social de Venezuela, tesis con mención publicación y suma cum laude. Doctora en Ciencias de la Educación en el Pedagógico de Caracas, con postdoctorado en Semiótica y Pragmática en la Universidad Complutense de Madrid, cuenta con proyectos financiados por la UPEL y con participación de la Universidad Complutense de Madrid, con proyectos financiados por el FONACIT. Investigadora certificada de la Universidad Complutense de Madrid, el grupo internacional CONCILIUM y del CELARG, ponente regular en eventos nacionales e internacionales, adscrita a la línea de investigación, Ciencias del lenguaje y con siete años de investigación en el área de análisis del discurso. Profesora Ordinaria de la Universidad Pedagógica Libertador. Investigadora acreditada del CYTED, la AECID, profesora de la UNIMET.
} 


\section{"El docente de hoy confronta la grave dificultad de que los textos de historia no le prestan ayuda; antes por el contrario, desvían la orientación del trabajo, siembran el desaliento en los alumnos que se hallan en un mar de nombres, fechas $y$, detalles insignificantes}

(Martínez y Vásquez, 1951, p. 69).

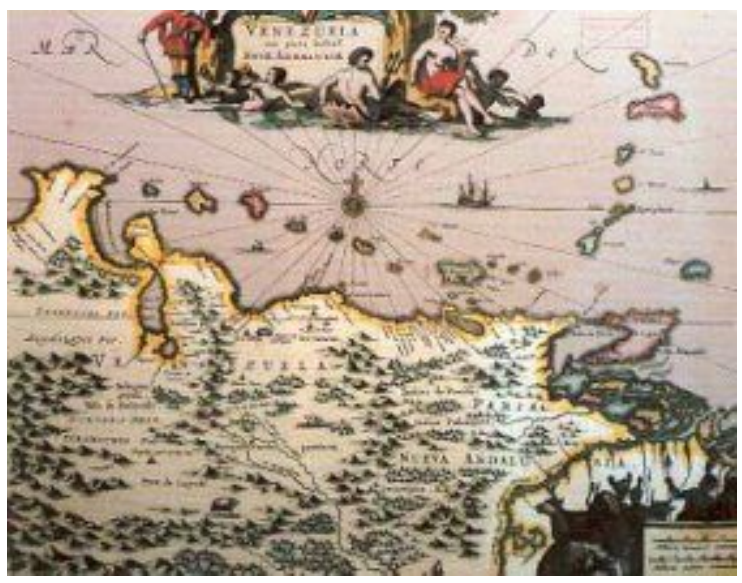

En la vida de los investigadores existe lo que me atrevería a denominar una silueta curricular, un objeto de estudio que nos acompaña evitando los esfuerzos disgregados, angustias que nos quitan el sueño, objetos de estudio que como una sombra nos acompañan al leer la prensa, al ver las noticias en la televisión, al pasear por los libreros de las universidades, amores inconclusos que nos marcan al investigar. Quien investiga sabe de lo que hablo, algunos tenemos la suerte de descubrirlo en pregrado, otros son atropellados por ellos en los diferentes postgrados al verse en la premura de presentar una tesis de maestría o doctoral.

Esos noviazgos infinitos, con los que nos peleamos al pensarlos agotados, pero con los que luego nos reconciliamos, son los problemas de investigación; tenerlos claros permite la sinergia de los esfuerzos, integrar los aprendizajes y las lecturas en una misma dirección, evitan el diletantismo de las energías y nos ponen a empujar en un mismo norte. Encontrar ese objeto de investigación es tan importante como la investigación misma, porque no puede encontrarse lo que no se sabe que se busca.

Yo me encontrado a lo largo de mi silueta investigativa personal con el trabajo de Bracho en momentos bien oportunos, y sus palabras, si bien es cierto no vienen de un historiador de oficio, vienen de lo que Melich (1999) ${ }^{1}$ denomina "el saber profano": en su práctica pedagógica y trabajando, en su rica experiencia con diversos textos de historia, ha logrado encapsular las características discursivas más importantes en el tratamiento de la Historia como constructo. Yo diría con mucho respeto y humildad que se trata de su noviazgo infinito.

Sin duda la preocupación por el instrumento ideológico en el cual el texto y los discursos históricos se han convertido, y cómo han logrado marcar, como una res a fuego, la concepción de la Historia, es una cuita constante en el trabajo de Bracho. Con tal peliagudo encargo autoimpuesto, Bracho va caracterizando el discurso de los textos y de la historiografía en general, puntualizando los aspectos que los definen y colocan ideológicamente en lugares algo incómodos. Y es que en Historia, como en muchas otras ciencias, los textos no cumplen sólo la loable misión de acarrear palabras vivas, de aquí para allá, a donde y a quien quiere, sino que a 
través de ellos se dibujan esquemas de ideas, en los cuales unos pueblos son legitimados y otros castigados a la oscuridad.

El discurso tiende hacia lo narrativo y anecdótico, propicio para la adecuación a una máxima positivista como es la de tomar en cuenta el cómo y no la explicación de por qué se suscitan ciertos fenómenos. En este orden, poco importa la génesis de éstos ni el papel que pueda desempeñar la esfera económica o social dentro de una sociedad, afirma Bracho (1996),2 esta su primera gran denuncia, si nos aproximamos a los hechos históricos y describimos prolijamente el cómo, podemos hacer de la historia sólo un relato, digno del mejor cuentacuentos. La Historia es un cuento, muchas veces matizado por detalles personales del autor del texto o del mismo docente que da la materia.

Los hechos parecen del pleistoceno desvinculados completamente de la realidad, del precio del pasaje, de las elecciones, de las diferencias sociales; están allí, como una especie de crónica o almanaque mundial al que podemos recurrir si se necesita, o si no queda más remedio. Sin preguntarnos el qué ni por qué dejamos inválida la ciencia histórica; su capacidad de moverse como bumerang del pasado al presente y viceversa no existe. Nuestros textos, según Bracho, abordan el hecho histórico de esa forma, el alumno la "estudia" como quien disecciona un sapo, la observa, la memoriza, pero no entiende los procesos coyunturales y estructurales que como en un eje de coordenadas coincidieron para generar los hechos.

En este sentido, apuntala Bracho que presentar el hecho histórico de esa manera debilita la conformación desde edades tempranas de una conciencia nacional, porque la Historia narrada en los textos parece una aproximación a la genética de la nación, a su origen, pero ese origen no es explicado en las razones intrínsecas de su formación. La Historia es recuerdo por excelencia, necesitamos como nación un pasado que recordar y en algunos casos hasta ciegamente venerar.

La Historia tiene que ofrecernos el fundamento del presente, así dejamos de ser huérfanos; hay padres y madres en la Historia, de hecho más padres que madres, pero padres que al fin nos dan sentido de pertenencia hacia un espacio, una bandera, un sueño en común. Sin duda alguna, esta Historia denunciada por Bracho no ofrece este vínculo con la otredad del pasado, presentada en los textos. Tanto el sentido de pertenencia, su recuerdo, su origen, como el convencimiento de nuestra existencia en una sociedad cambiante son parte de lo que conocemos como conciencia histórica. Bracho (2000). ${ }^{3}$

La conciencia histórica a la que Bracho alude, sin duda no se forma sólo con los textos, pero el texto la modela presentando, a través de su legitimación explícita, un discurso en apariencia inocuo pero que dibuja una imagen de lo que fuimos y somos.

Otro elemento sobre el cual Bracho se detiene a lo largo de sus producciones es el eurocentrismo, dentro del cual establece unas implicaciones en las cuales me gustaría detenerme. 
La ciencia social nació con la impronta occidental y la referencia de lo europeo septentrional como excepcional manifestación de lo virtuoso, lo bueno, lo exquisito, lo normal, lo avanzado, lo civilizado. Bracho (2002). ${ }^{4}$ Clarifica Bracho que cuando se refiere a eurocentrismo hace referencia a la Europa Occidental y los Estados Unidos de Norteamérica, como conjunto occidental, en términos de geocultura. Las ciencias sociales, al nacer en Francia, Alemania, Italia, Inglaterra y Estados Unidos de América, están marcadas en cuatro categorías en particular, citadas por Wallerstein $(2001)^{5}$

La historiografía: que según el autor ha sido el espacio desde donde se ha fijado una cronología "absoluta" en la que median hitos, fases o etapas. De esta forma se establecen categorías como historia y prehistoria, por poner un ejemplo. En ellas se establece de forma explícita e implícita que antes de la invención de la escritura no existe historia, sino prehistoria. La pregunta que me hago es: si el objeto de estudio de la historia es el hombre, y la prehistoria describe las acciones del hombre desde su aparición en la tierra, es confuso plantear que por el hecho de no haber fuentes escritas ese accionar del hombre no se considera historia.

Esa misma historiografía establece la periodización dividiendo el devenir en edades, delimitadas por hechos generalmente ocurridos en Occidente; de esta forma, de manera camuflada, se asume que cuando hablamos de Edad Antigua, estos atributos asociados a las llamadas civilizaciones: modo de producción, adelantos, estructura social, relaciones de producción, se asumen como presentes en el resto del mundo. En este sentido, agrega Morales (1994) ${ }^{6}$ "El peso de la concepción eurocentrista se despliega por las principales arterias del organismo sociocultural: la enseñanza oficial, la radio, la televisión, la prensa, los guías de turismo, se convierten en reproductores de estas formas de colonialismo cultural" (p. 8).

Por supuesto el surgimiento de este eurocentrismo en los manuales de historia y en los textos históricos en general, tiene cierto sentido si nos detenemos en el hecho de que quienes tienen la posibilidad de narrar lo ocurrido son los que primero tienen la posibilidad de escribirlo en los textos y además legitimarlo en las diferentes casas de estudios.

Desde esta perspectiva, todo aquello diferente a lo que ellos representan es aquello que se descubre, aquello que de manera muy sutil consideramos inferior. Continúa Morales $(1994)^{7}$ señalando que la concepción eurocéntrica supone la supervaloración de la organización económica, social y política de las naciones colonizadoras, como cualidades y aptitudes intrínsecamente óptimas y con una misión ecuménica: trasplantar a los pueblos "descubiertos" sus valores y patrones culturales.

La pregunta a este respecto sería, ¿cuánto de este eurocentrismo queda todavía en los textos escolares? ¿Hasta qué punto se siguen repitiendo estos nocivos credos al presentar la historia a los estudiantes? ¿Ha logrado desterrarse de la historiografía contemporánea esta carga de subestimación de lo nacional? Y lo que es más grave aún, ¿cuáles son las inferencias que el estudiante hace con respecto a nuestra posición en el mundo? 
Bracho $(2002)^{8}$ establece que la historiografía muestra cómo un orden lógico del mundo se ha creído y divulgado, estableciéndolo como el orden del mismo mundo. A esto se le agregan otras características que presentan a la historia $(1995)^{9}$ como centrada en las consecuencias y no en las causas, asumiendo un orden supranacional en el que nos corresponde jugar un papel periférico en las decisiones que afectan a nuestros pueblos. Dichas características son las siguientes:

- La carencia de una real articulación entre la enseñanza de la historia de Venezuela y un proyecto nacional, adecuado a nuestras necesidades.

- La poca preparación epistemológica de los que dictan clases de historia de Venezuela.

- La estructuración de programas instruccionales dirigidos sólo a informar y con objetivos desarticulados.

- La utilización de manuales ajustados a una teoría del conocimiento, que fracciona y divide.

- La utilización del discurso histórico como un medio para justificar el presente o el orden establecido.

- El uso de la enseñanza de la historia cual vía de penetración de conciencias.

- También cabría mencionar la desarticulación, evidente en los programas de enseñanza, entre las distintas disciplinas científicas (p. 99). ${ }^{10}$

De esta forma se nos vendió una idea de progreso y de civilización que sólo tiene sentido cuando se compara y se contrasta con la idea de civilización y de progreso presentada por esta historia oficial. Fue así como asumimos, de manera implícita, que más desarrollados somos en la medida en que más nos parecemos a Occidente, en la medida en que abandonamos las prácticas que la historia patria califica como "bárbaras".

La idea de progreso, tal como lo ha afirmado en otra oportunidad (2002), se ha alimentado de perspectivas acumulativas y lineales. Aparecen en el siglo XX en los espacios latinoamericanos, junto con la noción de orden, comparando de manera automática estructuras y estableciendo taxonomías que nos colocan en sincera desventaja. Cabría entonces preguntarse si el autoconcepto que forma el estudiante de sí mismo y de su país no ha bebido en estas fuentes, desfigurando la imagen que de él se presenta en el espejo de la historia.

Cuando el hijo de Marc Bloch lo increpa preguntándole para qué sirve la historia, ${ }^{11}$ el eco de la pregunta llega hasta los textos de hoy. Un mundo sumergido en la incertidumbre de la modernidad, donde nos diluimos como tinte en el agua, ¿tendrá sentido repetir esta historia que no nos define en la diversidad, sino que nos coloca como apéndice del mundo, del cual se puede prescindir sin remordimiento?

Las tendencias a la globalización contradicen a los movimientos nacionalistas. Por un lado las fronteras están cada vez más borrosas, el espacio y el tiempo han tomado dimensiones completamente nuevas (Harvey 1994, Giddens 1987), ${ }^{12}$ denuncian los analistas del discurso hablando de los discursos académicos. El texto como discurso académico puede en este caso no sólo repetir el discurso sino también engringolar el pensamiento del alumno, si no tiene la fortuna de ser enseñado por un docente que salga de él. 
De esta manera, prácticas de racismo del siglo XXI y otras prácticas xenófobas se cuelan como el agua en una pared, debilitándola por dentro. Esta retórica antigua pero siempre nueva utiliza diferentes estrategias, puede usar la imagen: carboncillos que muestran a los indígenas recostando su cabeza en el pecho de Colón y a él soberbio, con su cayado de poder temporal sembrado en la arena de la playa, usando un discurso comparsa del mundo occidental, se apuntala con unas actividades que ningún esfuerzo comprometido exigen del alumno. Todas estas, a la vez o por separado, configuran lo que hoy es el paradigma de una historia inútil, sin pertinencia a nuestra realidad multidimensional.

Habría que preguntarse al fin, si quienes enseñan historia responden a un llamado que debería ser vocación, o si sólo repiten lo que el texto dice. Sin duda, reflexiones como las de Bracho abofetean la conciencia, haciéndola, siendo optimistas, despertar.

\section{REFERENCIAS}

Bloch, M. (2000). Apología de la historia y el oficio del historiador. Caracas, Venezuela: Fondo de Publicaciones Lola de Fuenmayor.

Bracho, J. (2000). Currículum, identidad, nacionalidad. Caracas, Venezuela: Fondo Editorial Tropykos.

Bracho, J. (1996). El positivismo en la enseñanza de la historia. Caracas, Venezuela: Fondo Editorial Tropykos.

Bracho, J. (2000). Historia y Occidente. Algunas representaciones de la historiografía en el espacio de la modernidad. Caracas, Venezuela: Tierra Firme.

Harvey, D. (1999). Justice, nature and the geographic of diffence. Londres, Inglaterra: Blackwell.

Melich, J. (1999). La antropología cultural. Madrid, España: Paidós.

Morales, S. (1994). Eurocentrismo y descolonización de la historia. Caracas, Venezuela: Fondo Editorial Tropykos.

Wallerstein, E. (2001). Conocer el mundo, saber el mundo, el fin de lo aprendido. Una ciencia social para el siglo XXI. México: Siglo XXI Editores.

\section{Notas}

1. Melich, J. (1999). La antropología cultural. Madrid, España: Paidós.

2. Bracho, J. (1996). El positivismo en la enseñanza de la historia. Caracas. Venezuela: Fondo Editorial Tropykos.

3. Bracho, J. (2000). Currículum, identidad, nacionalidad. Caracas. Venezuela: Fondo Editorial Tropykos. 
4. Bracho, J. (2002). Historia y Occidente. Algunas representaciones de la historiografía en el espacio de la modernidad. Caracas: Tierra Firme.

5. Wallerstein, E. (2001). Conocer el mundo, saber el mundo, el fin de lo aprendido. Una ciencia social para el siglo XXI. México: Siglo XXI Editores.

6. Morales, S. (1994). Eurocentrismo y descolonización de la historia. Caracas: Fondo Editorial Tropykos.

7. Ibidem, p. 13.

8. Bracho, J. (2002). Historia y Occidente. Algunas representaciones de la historiografía en el espacio de la modernidad. Caracas: Tierra Firme.

9. Bracho, J. (1995). El positivismo en la enseñanza de la historia. Caracas: Fondo Editorial Tropykos.

10. Ibidem, p. 99.

11. Bloch, M. (2000). Apología de la historia y el oficio del historiador. Caracas: Fondo de Publicaciones Lola de Fuenmayor.

12. Harvey, D. (1999). Justice, nature and the geographic of diffence. Londres: Blackwell. 